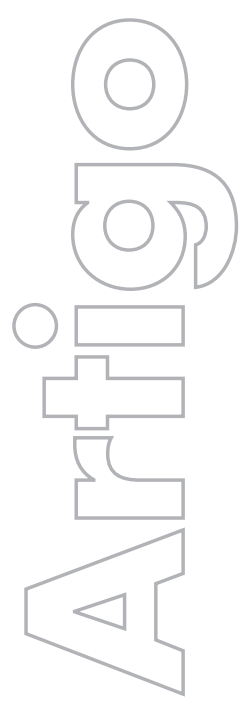

\title{
Lugar, corporeidade e política: reflexões a partir do net-ativismo em redes sociais online
}

\author{
Marcos Antonio de Moraes Xavier \\ Unila
}

\section{revista}



espaço e tempo

Volume $20 \cdot n^{\circ} 3(2016)$

Como citar este artigo:

XAVIER, M. A. M. Lugar, corporeidade e política: reflexões a partir do net-ativismo em redes sociais online. Geousp - Espaço e Tempo (Online), v. 20, n. 3, p. 551-567, mês. 2016. ISSN 2179-0892.

Disponível em: <http://www.revistas.usp.br/geousp/issue/ view/6465>. doi: http://dx.doi.org/10.11606/issn.2179-0892. geousp.2014.84539.

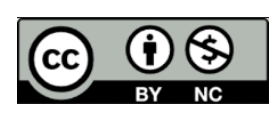

Este artigo está licenciado sob a Creative Commons Attribution 4.0 License. 


\title{
Lugar, corporeidade e política: reflexões a partir do net-ativismo em redes sociais online
}

\section{Resumo}

net-ativismo praticado em redes sociais online inaugura novas formas e estratégias de ação política, mas não extingue ou diminui a importância das relações face a face. Nos últimos anos, a ocupação de ruas e espaços públicos por multidões em diferentes lugares do mundo tem sido uma amostra desse fato. Provavelmente pelo fato de problemas, indignações ou solidariedades expressos nessas redes serem concretos nos lugares onde efetivamente as pessoas vivem, e não num espaço virtual metafórico. No lugar - espaço banal, extensão de coexistência e vizinhança -, as relações de reciprocidade são inescapáveis, pois, graças à nossa corporeidade, fazemos parte do campo prático da ação uns dos outros e juntos, ainda que de forma desigual, enfrentamos nossos problemas. É nele, portanto, que a produção da consciência política é mais verossímil e que a ação de luta pode se tornar efetiva.

Palavras-chave: Lugar. Corporeidade. Copresença. Net-ativismo. Redes sociais online.

\section{Place, corporeality and politics: reflections from the net-activism in online social networks}

\begin{abstract}
The net-activism in online social networks opens new ways and political action strategies, but does not eliminate the importance of face to face relationships. In recent years, the occupation of streets and public spaces by crowds in different parts of the world has been proof of this. Probably because of the problems, indignation and solidarity expressed in these networks are concrete in places where effectively people live, not in a metaphorical virtual space. In the place: banal space, coexistence extension and neighborhood, the reciprocal relationships are inescapable because like it or not, because of our corporeality, are part of the practical field of each other's action and together, although in unequal conditions, we face our problems. It is in place, so that political consciousness is more likely and that the action of struggle can acquire effectiveness.
\end{abstract}


Keywords: Place. Corporeality. Co-presence. Net-activism. Online social networks.

\section{O corpo na cidade}

Em seu ensaio sobre o corpo e a cidade, Richard Sennett observa um fato importante para iniciarmos esta interlocução sobre a relação entre os indivíduos, as redes sociais online e o lugar. Para ele, a mobilidade característica do homem moderno, cuja vida transcorre em cidades entregues à necessidade de rápida circulação, leva à perda das experiências sensoriais que lugares ou pessoas possam despertar, evitando, assim, qualquer relação visceral que esse mesmo homem julgue uma potencial ameaça a sua individualidade (Sennett, 2014, p. 262). Para ele, individualismo e velocidade amortecem o corpo e não permitem o estabelecimento de vínculos (Sennett, 2014, p. 327). Com o mesmo olhar acurado, Milton Santos já havia chamado a atenção para o fato de que "quem tem mobilidade na cidade e é capaz de percorrê-la velozmente acaba por ver pouco da Cidade e do mundo" (Santos, 1994, p. 84), mantendo uma comunhão maior com imagens pré-fabricadas, vinculadas ao consumo e ao conforto, que com a cidade que percorre.

Com o avanço das telecomunicações e da informática, essa celeridade do movimento na cidade passou a conviver com a celeridade das informações que possibilita e induz, por sua vez e paradoxalmente, certas formas letárgicas dos corpos. À velocidade da luz, os meios digitais de telecomunicação permitem a conexão de milhões de indivíduos situados em milhares de lugares. Cotidianamente, seus corpos podem permanecer horas imóveis diante de uma tela pela qual estabelecem uma multiplicidade de relações mediadas por um complexo sistema técnico capaz de armazenar, tratar e transmitir imagens, textos e sons.

O homem moderno das classes médias e abastadas vivencia, simultaneamente, experiências de celeridade e letargia. A primeira se manifesta pelo ritmo acelerado das inovações tecnológicas, das obsolescências programadas, da moda, dos consumos, das qualificações e desqualificações profissionais e do frenético fluxo das informações e do dinheiro. Já a segunda, corresponde às inúmeras manifestações de imobilismo, sedentarismo ou isolamento, abrigado em locais seguros, confortáveis e assépticos com os quais os indivíduos buscam proteger seu corpo de qualquer desconforto ou incômodo gerado por entornos que lhes pareçam caóticos, dissonantes ou ameaçadores para sua integridade física ou seu status social.

Em ambos os casos, acentua-se a possibilidade de alienação do indivíduo da totalidade urbana, de seu país e do mundo, pois o espaço público é vivenciado apenas como percurso e obstáculo a ser vencido em seus deslocamentos para chegar aos locais que frequenta. Fato agravado nas metrópoles dos países subdesenvolvidos, onde essas classes abastadas criam limites bem definidos à circulação de seus corpos e dos corpos dos outros, aqueles com quem não querem se relacionar. Os condomínios fechados (residenciais e corporativos), os shopping centers e clubes prives são exemplos. A serviço daqueles que vivem afinados com a velocidade com que se instalam as modernas formas hegemônicas de produzir, consumir e se relacionar, cujas origens são frequentemente alienígenas e distantes, esses condomínios negam a totalida- 
de da cidade, onde áreas obsoletas e desvalorizadas são ocupadas pela maior parte da população, que sobrevive de acordo com os limites de seus rendimentos, usando técnicas, formas de produzir e consumir menos modernas, com base numa racionalidade calcada na necessidade de, a cada dia, garantir sua subsistência.

De fato, para a maior parte da população, as cidades são viscosas. Seus corpos circulam por elas mais lentamente. $\bigcirc$ tempo concreto, vivido segundo as possibilidades de cada um, multiplica-se segundo escalas sobrepostas e entrecruzadas que constituem um emaranhado de trajetórias e temporalizações práticas de cadências singulares, pois cada um circula perfazendo traçados de diferentes geometrias e dimensões, sendo variando a duração e a frequência dos deslocamentos de acordo com os meios técnicos que acionam, disponibilizados conforme seus recursos financeiros e os lugares que habitam ou frequentam.

Expressão incontestável de nossa existência, nossos corpos se situam em diferentes lugares ao longo do tempo, a partir dos quais estabelecem suas relações. Os lugares que os corpos ocupam nas cidades, onde eles podem ou não se fixar, podem ou não circular, revelam a materialidade da distinção, da situação de cada indivíduo no seio de uma dada formação socioespacial, bem como as desigualdades que a caracteriza.

Se o lugar é uma extensão do acontecer solidário, espaço banal composto por todas as materialidades, todos os homens e todas as relações que compartilham um mesmo entorno (Santos, 1996, p. 160), a corporeidade não pode ser desconsiderada de sua constituição. Como observa Merleau-Ponty (2011, p. 268) "o corpo próprio está no mundo e forma com ele um sistema”. Expressão concreta da existência dos indivíduos, o corpo é uma inquestionável materialidade sensível e, justamente por ser materialidade, é um elemento do espaço banal, pois para cada um os corpos dos outros fazem parte do seu mundo. Não se trata de considerar o corpo como simples objeto, mas de compreendê-lo como a expressão visível de um Ego concreto, "um ser corpo atado ao mundo" (Merleau-Ponty, 2011, p. 205) que estabelece relações de reciprocidade.

Nos lugares, sobretudo no seio das grandes cidades, a copresença permite a consciência da existência real dos outros, de que eles fazem parte do meio em que vivo, de que eu sou parte do campo de ação deles e que, juntos, fazemos parte de uma realidade total compartilhada. A densidade demográfica estabelece uma verdadeira pressão humana e também adensa, indissociavelmente, o pensamento, a noosfera proposta por Theiard de Chardirn (1995). É a partir destas premissas que este ensaio explora as interfaces entre as redes sociais online, como meios de relações de corpos-ausentes, e a organização de eventos de massas promotores de encontros que parecem confirmar a pertinência da copresença nos lugares para a produção da política e a busca de protagonismo popular na elaboração do futuro, particularmente no âmbito das aglomerações urbanas.

\section{As tecnologias da informação e a simultaneidade e articulação dos eventos}

Ao propor a unicidade da técnica como um elemento constitutivo do atual processo de globalização, Milton Santos (1994, 1996, 2000) observou sua função como meio com o qual os atores hegemônicos da economia, da política e da cultura articulam simultaneamente inúmeros lugares do planeta em suas ações, conduzindo a uma convergência dos momentos propiciada 
pela teleação permitida pelos sistemas informacionais que garantem o comando unificado dos eventos. É assim que grandes empresas, a partir de suas sedes, podem colocar em funcionamento, simultaneamente, processos de produção, distribuição, comercialização e consumo em inúmeros lugares distantes. Para o autor, os fluxos de informações, ordens e comandos correspondem à solidariedade organizacional que conforma o que ele define como as verticalidades que fazem chegar aos lugares as decisões sobre o que fazer e como fazer.

Deste ponto de vista, as verticalidades, a serviço dos agentes hegemônicos, estariam no cerne da produção de espaços alienados (Isnard, 1982, p. 55) destituídos do comando político das ações que os utilizam como plataforma de investimento, um mero recurso (Gottmann, 2012) a serviço desses agentes. Indissociáveis dos espaços que abrigam uma alta densidade técnica, as informações emitidas pelos agentes hegemônicos e indutoras de ações obedientes a suas regras conformam densidades informacionais reveladoras do grau de exterioridade de cada lugar, bem como de sua propensão a entrar em relação com outros lugares (Santos, 2005, p. 160).

No entanto, o desenvolvimento acelerado das tecnologias da informação nos últimos 15 anos, vinculado à expansão e popularização da telefonia celular e à disseminação dos smartphones conectados às redes $3 \mathrm{G}, 4 \mathrm{G}$ ou wi-fi trouxeram outras possibilidades. Aplicativos (whatsapp, messenger e hangouts) e redes sociais (Facebook, Twitter, instagram, telegram) têm ampliado tanto a densidade informacional dos lugares quanto a referida propensão dos mesmos a se relacionarem uns com os outros, desde que as densidades técnicas e normativas (infraestrutura de rede, empresas provedoras e sistema regulatório) permitam a conexão e o uso destes aparelhos e outros dispositivos móveis como tablets e notebooks.

Hegemônicos por sua origem e propósitos, o sistema de objetos e ações constitutivos dessas redes informacionais induz novos comportamentos, formas de organização do trabalho, do consumo e da vida cotidiana, bem como de relacionamentos pessoais. Também corresponde a sofisticados meios de levantamento de informações e monitoramento de seus usuários. Constitui-se como verdadeiro panóptico digital a serviço das grandes empresas que acessam lugares frequentados, sites visitados, lista de contatos e ligações realizadas entre outras informações. $\bigcirc$ que permite identificar e classificar perfis de usuários/consumidores que, por sua vez, integrarão estratégias de indução a certos comportamentos alinhados aos interesses das empresas.

A rápida propagação destes objetos, a redução dos custos de aquisição e serviços, bem como a elaboração de aplicativos de fácil interação com os usuários têm permitido que estes mesmos meios sejam utilizados para uma comunicação instantânea entre indivíduos conectados que passam a estabelecer verdadeiros diálogos antes permitidos apenas em copresença. São exemplos o uso do whatsapp, do messenger e do hangouts, aplicativos que permitem interlocuções em texto e voz. Pelos mesmos meios e, principalmente, pelas redes sociais online, como Facebook, e Twitter, também foi tornado possível a produção, difusão e troca simultânea de informações sobre diferentes fatos, causas, pautas de luta e reivindicações, auxiliando na organização de eventos e definição de estratégias em conformidade com finalidades distintas daquelas da produção, da circulação e do consumo comandadas pelas empresas, acrescentando novos conteúdos e lógicas às verticalidades que incidem nos lugares. 
Mesmo sendo monitorada por grandes firmas globais como Google, Facebook e provedores de telefonia celular e internet, a comunicação digital via aplicativos para smartphones, redes sociais e blogs tem sido utilizada para a articulação de ações políticas a partir de diferentes lugares do planeta que se manifestam tanto na própria internet quanto nas ruas das grandes cidades. Como resultado, observa-se a ascensão do chamado ciberativismo, ativismo digital ou net-ativismo como forma de engajamento e ação política. Um sistema de ações e objetos cuja expansão e intensidade de seu uso tem sido acompanhado por transformações nas interações sociais cujas características, parecem, num primeiro momento, redefinir a função da proximidade e do lugar nas relações entre os indivíduos.

\section{Rede sociais online e net-ativismo}

As transformações sociais, políticas e econômicas associadas à internet têm sido objeto de investigação e reflexão de diversos autores de diferentes campos do conhecimento, escolas e posicionamentos teóricos, metodológicos e políticos. Entre estes, e em razão de inquietações bem precisas presentes neste ensaio, foram escolhidos, além de Manuel Castells $(2003,2013)$ e de Pierre Lévy $(1993,2001,2010)$, alguns teóricos da comunicação que se dedicaram a analisar uma das faces da internet, as redes sociais online (facebook, blogs, twitter) e sua relação com o net-ativismo (Bustamante, 2010; Di Felice, 2013, 2015; Lemos, 2013; Martino, 2014; Roza, 2012; Silveira, 2009; Sorj, 2003). Essa escolha se deve ao fato de esses autores trazerem proposições sobre a dimensão espacial do tema que devem ser debatidas com a geografia por tocar em questões centrais para esse campo do conhecimento, relativas à natureza do espaço geográfico e à própria condição da existência humana atrelada a ele.

Para o início desta discussão, é importante atentar para a divisão básica na relação entre política e internet: a política da internet e a política na internet (Silveira, 2009, p. 103). Enquanto a primeira envolve a infraestrutura, os conteúdos, os formatos e as aplicações, incluindo seus modos de regulação, a segunda está associada à política que se faz na rede, seja por partidos, organizações coletivas ou indivíduos, tornando a mesma uma esfera pública de troca e difusão de informações, de diálogo, realização e organização de ações com os mais diversos propósitos. Ambas, de maneira distinta, envolvem o ciber ou net-ativismo, que utilizaremos aqui como sinônimos dos ativismos e movimentos sociais que utilizam a internet para interlocução, elaboração de estratégias e organização.

- cirberativismo associa-se a própria expansão da internet correspondendo a como um conjunto de práticas realizadas nas redes cibernéticas em defesa de diferentes causas políticas (Silveira, 2010, p. 31), cujas novas tecnologias da comunicação são aliadas "para o fortalecimento das organizações, para a coordenação de campanhas e protestos, para a difusão de informações, denúncias e petições" (Di Felice, 2013, p. 54). Ele se desdobra em dois tipos de ação. De um lado, a chamada cultura hacker, que, em defesa da liberdade irrestrita de acesso à informação, trava combate no campo dos protocolos da rede (TCP/IP, HTTP) e códigosfonte livres para softwares, enfrentando o controle dos Estados e das empresas por meio de estratégias baseadas num individualismo colaborativo de inspiração liberal e meritocrática, ${ }^{1}$

1 Um exemplo é o desenvolvimento de softwares livres, cujos criadores colaborativos não buscam equidade ou justiça social. Por vezes, movidos pelo anarco-capitalismo, entendem que o desenvolvimento colaborativo de códigos aproveita 
sendo um dos exemplos o WikiLeaks, cuja invasão de sistemas governamentais e de grandes empresas visa acessar e tornar públicos documentos confidenciais julgados imprescindíveis ao conhecimento público. De outro lado, envolve os partidos, gestores públicos, parlamentares, coletivos, movimentos sociais organizados e indivíduos que procuram fazer política na internet difundindo informações e estabelecendo interlocuções e estratégias via blogs e redes sociais como facebook e twitter. É para esta segunda forma de ativismo realizado via internet que esta reflexão chama a atenção.

Para Di Felice (2013), o ativismo digital não se restringe ao uso da internet como suporte para a difusão e troca de informações. De sua perspectiva, diante da capacidade interativa da banda larga e das redes sociais online, delineia-se uma nova forma de interação designativa da conectividade característica da ação social em redes e nas redes, que se desenvolvem segundo três fases do net-ativismo² (Di Felice, 2013, p. 54): a primeira, associada ao advento da internet, tornando possível a divulgação e compartilhamento de textos que propiciou as primeiras ações de alcance global de internautas; a segunda, marcada pelas primeiras manifestações de conflitos sociais pela internet e a terceira, caracterizada pela Web 2.0 (banda larga), pelas redes sociais online, pela difusão dos smarthphones e da conexão wi-fi e que se expressam em movimentos de protestos e subversões, além de redes de ativismo e colaboração.

Enquanto a primeira etapa é marcada pelos ativismos constituídos por movimentos internacionais temáticos, baseados em redes centralizadas, a segunda é perfilada pelo pluralismo temático manifesto em redes descentralizadas, mas comunicantes, a exemplo dos encadeamentos promovidos pelo movimento Zapatista (1994) e de Seattle (1999), mas também por outros movimentos diversos que não visam a tomada de poder ou processos revolucionários. A terceira e atual fase é marcada pelas formas reticulares autônomas e colaborativas de ativismo, que, segundo Di Felice (2013, p. 57), são responsáveis pela implementação de processos radicais de transformação, como a Primavera Árabe, ou pelo advento de novos atores e de amplos movimentos contra os partidos políticos e a corrupção, como o Occupy Wall Street (2011) e as manifestações de junho de 2013 no Brasil. Tratar-se-ia de um novo protagonismo tecnossocial que delineia novas formas de ação nas redes interativas digitais (Di Felice, 2013, p. 58).

Segundo pesquisa internacional realizada pelo Centro de Pesquisa Atopos, da Escola de Comunicação e Artes da Universidade de São Paulo, com apoio da Fapesp, entre 2011 e 2013, citada por Di Felice (2013), foram identificadas as seguintes características comuns das ações net-ativistas da terceira fase: (1) as ações têm origem nas redes digitais e continuam nas ruas das cidades sem deixar sua dimensão informativo-digital, sendo a qualidade dessas ações e sua eficácia mais relacionadas a suas capacidades conectivas atópicas ${ }^{3}$ do que a sua localiza-

melhor as possibilidades interativas disponíveis nas redes, sendo, portanto, mais eficaz. Consideram "que o modelo hegemônico de propriedade intelectual, centrado no bloqueio de acesso ao código-fonte, gera softwares de qualidade inferior" (Silveira, 2010, p. 32). Como a busca é por eficácia, destacam-se nas comunidades hackers aqueles de melhor performance.

2 Termo que deu título ao livro de Ed Schwartz para referir-se às redes cidadãs de participação política discutidas pelo autor e ao qual Di Felice propõe requalificar para incluir o que entende ser um ativismo em rede e na rede (Di Felice, 2011, p. 8)

3 Conforme Di Felice (2013, p. 67), atópico "é um termo grego que expressa a junção do prefixo alfa "privativo" com a palavra topos (lugar) que não remete à ausência de lugar, mas a uma localidade estranha, uma localidade fora do local, uma localidade indizível". 
ção geográfica, (2) a não linearidade das ações que resultam da sinergia de diversos actantes ${ }^{4}$ (circuito informativo, dispositivos, smarthphones, câmaras digitais, gravadores, redes sociais, movimentos socais e indivíduos), (3) a valorização do anonimato, (4) a recusa de uma identidade política, ideológica ou inspirada em líderes ou figuras carismáticas e (5) a recusa da institucionalização, expressa na aversão a partidos políticos e a ser tornar uma política institucional.

Pierre Lévy profetiza um novo mundo emergente da crescente conexão em rede daqueles que define como planetários. ${ }^{5}$ Defende que a conexão em rede potencializa a liberdade, a criatividade e a intersubjetividade, segundo uma competição cooperativa capaz de, graças à economia de mercado, propiciar interações que conduzam à constituição de uma verdadeira consciência planetária, com base no amor universal. Segundo ele, essa capacidade da rede tem origem no desenvolvimento da informática pessoal desencadeado pelo movimento social estadunidense Computers for the People, que propôs colocar a potência de cálculo dos computadores nas mãos das pessoas, visando justamente ampliar o acesso a uma potência técnica até então monopolizada pelas grandes instituições burocráticas públicas ou privadas (Lévy, 2010, p. 127). Para o autor, é a partir desse princípio que os movimentos dos anos 1980 relativos à comunicação baseada na informática inauguraram o ciberespaço "como prática de comunicação interativa, recíproca, comunitária e intercomunitária, como horizonte de um mundo virtual vivo, heterogêneo e intotalizável (por não se tratar de estrutura, mas de interações múltiplas em constante transformação), no qual cada ser humano pode participar e contribuir" (Lévy, 2010, p. 128).

Nesta perspectiva, o ciberespaço corresponderia a uma tecnologia intelectual que permite a elaboração de uma inteligência coletiva que resulta de redes complexas onde interagem um grande número de atores humanos, biológicos e técnicos, "segundo uma relação simétrica entre homens e coisas que não respeitam distinções entre coisas e pessoas, sujeitos pensantes e objetos pensados, inerte e vivo" (Lévy, 1993, p. 137). Assim, estabelecer-se-ia uma ecologia cognitiva que não nega ou rebaixa o papel do sujeito, fazendo proliferar as subjetividades por interações que são movidas por projetos, dotadas de sensibilidade, de memória e de julgamento (Lévy, 1993, 151).

Para Di Felice (2013) e Lemos (2013), em interlocução com a teoria do ator-rede, proposta Bruno Latour, da qual também comunga Pierre Lévy, a ação net-ativista associa-se à conformação em rede na qual não encontramos sujeitos sociais e lugares definidos, mas actantes humanos e não humanos em situação de ubiquidade atópica, segundo uma ecologia constituída no ato conectivo. $\bigcirc$ conceito de rede pode ser pensado:

[...] como a assunção de uma epistemologia que supera os conceitos de social e de sociedade, assim como elaborados pela cultura ocidental que os limitou ao âmbito da polis, isto é, do espaço antropomorfo da cidade, lugar restrito da disputa e dos conflitos das ideias (Di Felice, 2013, p. 64).

4 Termo da semiótica com que Bruno Latour designa os não humanos que atuam com humanos em redes de forma simétrica (Latour, 2001).

5 Para Pierre Lévy (2001, p. 15-17), são planetários todos aqueles para os quais o mundo corresponde ao campo de ação. Aqueles que dirigem os mesmos carros, usam os mesmos celulares, navegam na internet pelos mesmos computadores, ouvem música ou consomem alimentos dos mais variados lugares do mundo. Aqueles que trabalham em empresas transnacionais, na diplomacia, na tecnologia de ponta, na pesquisa científica, nas mídias ou na publicidade. Aqueles que circulam pelo mundo a trabalho ou por lazer. Os que, em síntese, correspondem à elite que pode usufruir as múltiplas possibilidades de investimento, trabalho e consumo disponibilizado pelo capitalismo globalizado. 
Por isso, Martino (2014, p. 57) destaca o fato de a estrutura das redes sociais na internet ser constituída por atores e nós, os atores não sendo necessariamente humanos, pois a palavra ator está ligada à própria ação. Nas redes, quem adquire relevo é a relação, não apenas entre indivíduos, mas também entre relações, isto é, uma perspectiva mútua e recíproca sobre a maneira como os atores interagem.

Tal perspectiva compreende a ação não a partir de um sujeito político, social e histórico, mas como realização de um ator-rede constituído pelas associações simétricas entre actantes humanos e não humanos imersos em uma condição habitacional atópica estabelecida "pelas trocas de fluxos informativos entre indivíduos, dispositivos de conectividade, banco de dados, circuitos informativos e territorialidades" (Di Felice, 2013, p.65). Uma ação originada nas redes, no ecossistema digital (Bustamante, 2010), o ciberespaço "como espaço abstrato e relacional em formação permanente pela articulação de objetos, humanos e não humanos" (Lemos, 2013).

Segundo esta premissa, as manifestações organizadas nas redes online que ocupam as ruas das cidades só acontecem de fato se permanecerem e forem postadas na rede. Por isso, nas ruas, os manifestantes continuam conectados às redes decidindo suas estratégias por meio de interações contínuas. Filmam, gravam e fotografam o que podem e imediatamente colocam tudo na rede para o mundo ver, tornando a manifestação novamente digital (Di Felice, 2013, p. 65). Fato que leva o autor a considerar inadequada a distinção entre espaço físico e espaço informativo, pois:

[...] a ação conectada digitaliza as ruas e as cidades para ganhar uma indefinível localidade e se reproduzir aquém dos espaços urbanos e político. Os conflitos são informativos, as passeatas são hoje games interativos que promovem a interação entre informações, espaços urbanos e ações, jogos de trocas entre corpos e circuitos informativos (Di Felice, 2013, p. 65).

A imprecisão das localizações, definida pela condição habitacional atópica das ações, seria então decorrente da coexistência conectiva entre os lugares - os espaços banais da geografia - e o sistema informativo digital, levando a ação a ser, ao mesmo tempo, e indissociavelmente, material e imaterial. Por essa proposta de entendimento de Di Felice, o ciberespaço não anula o lugar, mas torna imprecisa a identificação do lugar da ação.

Segundo um raciocínio similar, Lemos (2013, p. 61) compreende o espaço como rede relacional atravessada por fluxos de coisas e lugares em mutação, de tal forma que não há uma coisa meramente local ou global, pois as coisas ao nosso redor e as informações que chegam até nós s de diferentes espaços e tempos. Sendo assim, tudo seria localizado por atravessamento e circulação, nada sendo dominante o bastante para ser global, nem autossuficiente para ser apenas local, dando-se as ações segundo itinerários bizarros dos actantes implicados nas redes (Lemos, 2013, p. 63). Já para Castells (2013, p. 106), a forma de comunidade territorial não desapareceu, mas a proximidade geográfica perdeu a proeminência na configuração das relações sociais. As redes passam a substituir os lugares como suportes da sociabilidade nos bairros e nas cidades, pelo fato de os laços significativos dessas redes serem constituídos mais com base em relações de afinidade do que de proximidade. 
De fato, nosso cotidiano nas grandes cidades se dá em rede fazendo com que nossas relações de vizinhança sejam mais fracas, pois este cotidiano envolve vínculos, percursos percorridos e conexões entre pessoas e locais próximos e distantes em nossas ações e diferentes relações no âmbito do trabalho, do lazer, do consumo e da familia entre outros. Todavia, é preciso atentar para o fato de que se nossas relações com colegas de trabalho, amigos, familiares e grupos de interesse são mais fortes que as de vizinhança, o são, também, pelo fato delas acontecerem nos lugares, ali onde estamos juntos ou a partir de onde nos conectamos. Os fluxos não apenas atravessam os lugares. São constitutivos dos mesmos ao mesmo tempo que são produzidos a partir deles. Como veremos a seguir, segundo a perspectiva geográfica aqui esposada, considera-se o corpo e o lugar manifestações concretas da existência e, como tais, condições inalienáveis da vida e da ação dos sujeitos. Toda a ação, inclusive por meio dos sistemas interativos digitais, tem origem nesse espírito-corpo que é cada indivíduo, sempre a partir de uma localização que o situa em um lugar, sem os quais a ação mesma não ocorreria.

\section{A ocupação das ruas: corpo, lugar e efervescência das emoções}

Os eventos de múltiplas naturezas organizados e agendados via redes sociais online reforçam a importância de estar aí com meu corpo em copresença com outros que se afinam com causas iguais, próximas ou afins às minhas ou que discordem delas. Se minha vida é uma realidade radical pelo fato de ninguém poder senti-la ou vivê-la por mim, como assevera Ortega y Gasset (1973), é na copresença que o ser no mundo identifica no outro um espírito-corpo, Ego, que também o está observando. Nesses olhares cruzados, firma-se a condição de viver em coexistência em um mundo de relações interindividuais, pois:

[...] viver significa ter de ser fora de mim, no absoluto fora que é a circunstância ou o mundo: é ter de, querendo ou não, enfrentar-me, chocar-me, constantemente, incessantemente com quanto integra esse mundo [...]. Não há remédio (Ortega y Gasset, 1973, p. 86).

Por esse motivo, Sartre (1995, p. 261) destaca que, diante da escassez, como uma tensão e um campo de força nos quais se estabelecem relações de reciprocidade, "cada um existe e atua no interior do campo definido na presença de todos e de cada um".

Ainda que as tecnologias e redes digitais permitam a comunicação em tempo real, fazendo fluir pelas redes ordens, diretrizes, pensamentos e até mesmo emoções que levam outros a agirem, essa ação à distância, a teleação, só se realiza efetivamente no lugar; aquele onde está cada um implicado na ação. $\bigcirc$ que chega até nós via redes digitais são apenas latências que podem ou não conduzir à realização da ação, tornando-se existência sempre em algum lugar onde de podem observar sua manifestação, datação e duração. As topologias não são apagadas, permitindo sempre identificar os nós, localizações situadas nos lugares articulados nas redes, pelos quais os sujeitos as vivenciam, mas também as criam. As redes não são pura relação de relações, mas relações estabelecidas por sujeitos por meio de objetos que, por sua vez, interagem de forma sistêmica, justamente graças às ações desses mesmos sujeitos. Como observou Sartre (1995, p. 305), é pelas mediações dos homens que os objetos materiais se comunicam entre eles. 
Como observa Ortega y Gasset, meu corpo não me permite ser ubíquo, pois me põe em um lugar e me exclui dos demais. Me prega em um dado lugar e me desterra do resto. Atado ao mundo, meu ser corpo é um ser no espaço (Merleau-Ponty, 2011, p. 205). Logo, sempre que ajo, o faço a partir de um lugar. As coisas do mundo só posso vê-las, ouvi-las ou tocá-las de onde estou. $\bigcirc$ espaço virtual é apenas uma metáfora para o fluxo comunicacional incessante pelo qual estabelecemos relações a partir de onde efetivamente estamos. $\bigcirc$ meu aqui é o lugar onde eu corpo estou. "Aqui e eu, eu e aqui, somos inseparáveis" (Ortega y Gasset, 1973, p. 111).

A rede informacional não me retira dessa realidade radical que é meu corpo aqui, neste lugar, pois é por meio dele e do smarthphone ou notebook que me faço virtualmente presente para outro que está com seu corpo em outro lugar, onde não posso estar - lá onde ele efetivamente existe, como eu existo aqui. $\bigcirc$ que as tecnologias da informação permitem aos nos conectarmos a uma rede, a exemplo da realização de uma teleconferência, é tornar empírica a percepção do que não está aqui; termos consciência da existência do outro que está lá, com seu corpo e toda a materialidade que o circunda, e, assim, nós dois podermos agir onde estamos de maneira convergente. Trata-se da unicidade do tempo pela qual "o mesmo momento pode ser usado a partir de múltiplo lugares; e todos os lugares a partir de um só deles" (Santos, 2000, p. 28). Por imposição da nossa corporeidade, toda ação é uma ação efetiva apenas no lugar.

Como observa o filósofo Francisco Ortega (2007, p. 383), os discursos do póshumanismos, ${ }^{6}$ tecnobiomedicina e cyborglogias e do construtivismo sociodiscursivo do corpo compartilham uma visão dualista que separa mente e corpo, rejeitando tanto sua materialidade quanto sua experiência subjetiva. Assim, o corpo torna-se maleável, podendo ser reformado, modificado ou reconstruído por cirurgias plásticas ou mercantilizado em partes, graças às novas tecnologias reprodutivas, de manipulação genética e de transplante de órgãos. Conforme esses mesmos discursos, o corpo seria também uma prisão, um empecilho do qual a mente escaparia ao navegar pela internet, onde múltiplos corpos e mundos virtuais permitiriam concretizar o paraíso na Terra: "um mundo sem espessura de carne, deambulando no espaço e no tempo de forma angelical, sem que o peso da matéria sirva de obstáculo ao seu avanço" (Ortega, 2007, p. 384).

Destarte, na contracorrente, Ortega destaca o fato de a "materialidade do corpo designar nossa finitude e localização inescapável no tempo e no espaço, na história e na cultura”. É por isso:

[...] que a propagada dissolução do corpo acontece na forma de uma resistência diante do fato de que estamos sempre em algum lugar, nosso "aquil" e "agora" que define nossa conditio humana histórica. [...] o corpo ocupando o lugar central no mundo experienciado como "centro de visão, centro de ação, centro de interesse" (Ortega, 2007, p. 385).

6 Pós-humanismo corresponde a um movimento no qual, por meio da inteligência artificial, da nanotecnologia, da engenharia genética e de outras tecnologias, pretende-se gerar "'pessoas' possuidoras de capacidades físicas e intelectuais sem precedentes, como entidades possuidoras dos princípios de sua autoformação e de um caráter transcendente, porque potencialmente imortal, seja cyborgue ou máquina de inteligência artificial" (Rüdiger, 2007, p. 3). 
Sobretudo nas grandes cidades, onde os lugares são marcados pela sobreposição das densidades (humanas, técnicas, normativas, informacionais e comunicacionais), cheias de gente, de tal forma que nossos olhos vêm multidões por toda parte (Ortega y Gasset, 2007, p. 42), a coexistência de milhões de indivíduos nos obriga a aprender a lidar com o outro, como assevera Teilhard de Chardin (1995) e também a estabelecer negociações, cotidianamente. Nelas, a elogiada lentidão do movimento proposta por Milton Santos (1994) se contrapõe tanto à letargia característica dos imobilismos quanto à celeridade dos deslocamentos, das obsolescências, das modas, das inovações, da produção, do consumo e do dinheiro.

Para os sujeitos, letargia e celeridade parecem ser imobilizadoras. Já o movimento lento, imposto pela viscosidade da cidade e de suas irracionalidades, em relação à eficácia das ações esperadas pelo Estado e pelo mercado, pode ser considerado uma condição para encontrar a elaboração de alternativas por meio de caminhos de desvio, mudança e alteração, permitindo a produção de consciência que exige e permite a reflexão para agir:

[...] independência e autonomia só despertam quando há alguma impureza, dificuldade e obstrução, como partes da sua própria experiência [...] a resistência constitui uma experiência necessária e fundamental para o corpo humano, por meio dela, o corpo é despertado para o mundo em que vive (Sennet, 2014, p. 314).

Como condição de existir no mundo e que nos remete à irrefutável realidade de sermos espaciais, a corporeidade revela a potencialidade política do lugar como extensão do acontecer solidário onde encontramos objetos, corpos e ações com os quais estabelecemos relações de proximidade, coexistência ou reciprocidade. Reciprocidade que implica que "o Outro seja meio na exata medida em que eu mesmo sou meio, quer dizer, que seja meio de um fim transcendente e não meu meio" (Ortega y Gasset, 1973, p. 245), pois implica nós dois.

Em sua crítica ao capitalismo hodierno, Jonathan Crary (2014) observa que o uso criativo de novas ferramentas tecnológicas pelo ativismo político não deve pressupor que elas mesmas tenham valores redentores ou de capacidades mágicas que possam redimir automaticamente os fracos e oprimidos. Nem poderiam. As redes online são suportes de laços fracos, frequentemente efêmeros. As pessoas podem se ligar ou desligar a qualquer momento, mudar de interesse, não revelar sua identidade e migrar para outros padrões online (Castells, 2003, p. 108). Além disso, contrariando a leitura visionária de uma hiperdemocracia planetária potencializada pelas redes virtuais (Lévy, 2001), lembramos que a infraestrutura da internet "pode ter donos, seu acesso ser controlado e seu uso ser influenciado por interesses comerciais, ideológicos e políticos" (Castells, 2013, p. 226) e que "os centros de poder, concentradores de recursos políticos, culturais e econômicos, continuam a impor sobre a sociedade uma desigual distribuição de decisões" (Sorj, 2003, p. 56).

Jonathan Crary (2014), também alerta para o fato de que se as redes não estiverem a serviço das relações já existentes, forjadas a partir de experiências e proximidades compartilhadas, apenas reproduzirão e reforçarão as segregações, a opacidade, as dissimulações e o interesse próprio ao seu uso. Por isso considera que "qualquer turbulência social cujas fontes primárias estejam no uso das mídias sociais será historicamente efêmera e inconsequente", 
sendo um exemplo desta assertiva, o Movimento Brasil Livre (MBL), um dos ícones dos movimentos reivindicatórios alicerçados em redes sociais online, cuja origem efetiva ainda é objeto de indagação.

Nessa mesma direção, o olhar crítico de Rafael Santos de Oliveira sobre o uso de tecnologias digitais para o exercício da cidadania o faz observar que os vínculos estabelecidos pelas relações via redes sociais online são frágeis, "gerando manifestações de pertencimento ou simpatia com determinado movimento sem vir acompanhado de uma prática efetiva de ações passíveis de mudar uma determinada situação política" (Oliveira, 2011). Uma amostra são as petições online propostas a partir de sites como Avaaz.org, Activism.com e Change.org, o que os estadunidenses chamam de ativismo de sofá, que se faz por compartilhamentos, posts e curtidas. Uma manifestação da letargia dos corpos, a qual nos referimos antes, ações pontuais que não exigem movimento, tempo de dedicação e o efetivo engajamento.

À sua crítica, Crary acrescenta os riscos decorrentes do uso das redes e aplicativos digitais como mediadores de nossas relações. Para ele, a responsabilidade por outras pessoas que a proximidade implica passa a poder ser contornada pela administração eletrônica de nossas rotinas e contratos diários, conformando uma "atrofia da paciência e da deferência individual que são essenciais para a democracia direta: a paciência de escutar os outros, de esperar nossa vez de falar" (Crary, 2014, p. 14). ${ }^{7} \bigcirc$ e-mail, por exemplo, pode ser um instrumento fácil de se fazer presente à distância, sem precisar se "envolver em uma interação mais profunda para a qual não se dispõe de energia emocional" (Castells, 2003, p. 109). Provavelmente por isso, Agamben expressa sua raiva por outro meio de comunicação à distância - o telefone celular -, por considerar que ele modelou o comportamento dos indivíduos de cima abaixo, fazendo ainda mais abstratas as relações entre as pessoas (2010, p. 42).

Mas as tecnologias por si mesmas não sã capazes de produzir ou determinar as razões, os sentidos e as emoções implicados na ação. Sem desconsiderar os riscos efetivos apresentados acima, ao analisar os movimentos socais na internet, como os que levaram à ocupação da praça Tahir, no Cairo, ao Dia da Fúria, em diversos países árabes, e os Indignados na Espanha, todos no ano de 2011, Manuel Castells observa que a mudança social envolve uma ação que, em sua essência, é emocionalmente motivada. Ação que envolve o sentimento de raiva, pela indignação diante das condições de vida, que tornam insustentável a existência cotidiana para a maioria das pessoas, e o sentimento de medo, o qual a superação se dá pelo compartilhamento e pela identificação com os outros que têm os mesmos anseios, segundo um processo de ação comunicativa que faz prevalecer, segundo ele, "a mais poderosa emoção: o entusiasmo" (Castells, 2013, p. 162), que leva os indivíduos a se conectarem as redes transformando-se num ator coletivo consciente.

Tem sentido a observação de Roza (2012, p. 61) sobre o resgate da emoção para a análise das mobilizações sociais pela veia durkheimiana da ritualidade e da efervescência coletiva, encontradas nas formas elementares da vida religiosa. Por esse caminho de compreensão:

[...] as mobilizações seriam momentos rituais fundamentais para reforçar os laços sociais, e as representações coletivas, ao mesmo tempo em que atualizam sua experiência na prática de vivenciá-lo. $\bigcirc$ que se reitera é o próprio fundamento de coesão e dos laços sociais (Roza, 2012).

7 Para ele, os blogs são um exemplo do "triunfo do modelo unidirecional de diálogo consigo mesmo, no qual a possibilidade de jamais ter de esperar e escutar outra pessoa foi eliminada". 
Agamben (2010) sugere um método interessante para o tratamento teórico das redes sociais online e dos blogs, bem como de suas bases móveis (smarthophones, notebooks, tablets e rede $\left.w i-f_{i}\right)$, que permite superar a polarização entre visões apologéticas ou refratárias: tratase do conceito de dispositivos, que ele define como sendo "qualquer coisa que tenha de algum modo a capacidade de capturar, orientar, determinar, interceptar, modelar, controlar e assegurar os gestos, as condutas, as opiniões e os discursos dos seres viventes" (Agamben, 2010, p. 40).

Como dispositivos, as redes sociais online não se constituiriam como ecologias, ambiências ou espaços virtuais. Nem como um determinante da ação. Elas correspondem à classe de existência ${ }^{8}$ com a qual relação corpo a corpo com os viventes (indivíduo/substância) leva à constituição dos sujeitos com múltiplos processos de subjetivação. $\bigcirc$ que, segundo entendimento aqui proposto, situa as redes sociais online como uma entre outras condições das ações que, por sua vez, seguem se dando pelo meu corpo no lugar, onde efetivamente ele está em situação de copresença e contiguidade com outros corpos, objetos e ações.

Por essa perspectiva, não é possível concordar, portanto, com Di Felice, quando observamos acima que ele considera que as ações dos movimentos sociais, indivíduos e grupos ativistas têm origem na rede, segundo uma recursividade que remete ao constante retorno à mesma via de digitalização dos acontecimentos nas ruas da cidade, só assim se estabelecendo como realidade efetiva e eficaz. Tampouco com Lemos (2013, p. 59) quando afirma que a descontinuidade nas relações face a face, propiciadas pela internet e o celular, engendram processos desterritorializantes. Sorj (2003, p. 56) destaca que, diante dos intercâmbios propiciados pela internet, os espaços territoriais continuam "a ser tão importantes, ou mais do que nunca, não apesar de sua materialidade, mas por causa dela".

Os atuais movimentos sociais são conectados em rede de múltiplas formas não apenas online. Para Castells (2013, p. 164):

Embora esses movimentos geralmente se iniciem nas redes sociais da internet, eles se tornam um movimento ao ocupar o espaço urbano [...] $\bigcirc$ espaço do movimento é sempre feito de uma interação do espaço de fluxos na internet e nas redes de comunicação sem fio com o espaço dos lugares ocupados e dos prédios simbólicos visados em seus atos de protesto.

Segundo sua perspectiva, o resultado seria um hibrido de cibernética e espaço urbano que constitui um terceiro espaço: o espaço de autonomia cuja internet, como tecnologia que encarna a cultura material, é uma plataforma privilegiada, mas que, ao mesmo tempo, só pode ser exercida como força transformadora ao desafiar a ordem institucional disciplinar reclamando o espaço da cidade para seus cidadãos (Castells, 2013, p. 165).

Segundo a ótica aqui defendida, como já observado acima, a ação, dada a realidade radical que é a vida indissociável do corpo e de seu entorno material, tem origem no sujeito, cuja localização o situa sempre e inescapavelmente num determinado lugar, a partir do qual age.

8 Giorgio Agamben propõe uma divisão do existente em dois grandes grupos ou classes: os seres viventes (ou substâncias) e os dispositivos em que estes são capturados. Os sujeitos resultam da relação entre essas duas classes sobrepondo-se ao vivente, mas não completamente. É dessa forma que, segundo ele, "um mesmo indivíduo (substância) pode abrigar diferentes subjetivações: o usuário de telefones celulares, o nevegador na internet, o escritor de contos, o apaixonado por tango, o não global etc." (Agamben, 2010, p. 40). 
As redes sociais online não são entidades dotadas de vida própria, ainda que nelas se constitua uma ecologia das interações que adquire certa autonomia. Elas são meios pelos quais emito e recebo e, portanto, permuto com os outros (indivíduos, movimentos sociais, instituições, empresas) informações, textos, imagens e sons, permitindo que meu agir e o agir deles sejam articulados ou mutuamente referenciados em situações de conflito ou cooperação.

No lugar, as ações se redefinem e adquirem novos significados graças a esta convergência dos momentos propiciada por estas redes, como observa Milton Santos (1996, 2000). Mas é graças às relações de reciprocidade face a face que a produção de sentido pode ser profunda e duradoura. Juntos, segundo afetividades de empatia ou conflito, nos tornamos, em conjunto, potencialidade e força. Presença que se efetiva como massa corpórea que ocupa, desajusta e incomoda o alvo da ação política e que não pode ser simplesmente desplugado ou deletado.

\section{Um resultado: as redes e a densidade dos lugares e dos eventos}

Entendendo que cada lugar se define por sua existência corpórea e por sua existência relacional, Milton Santos (2005, p. 158) propõe distingui-los segundo suas densidades em técnica, informação e comunicação. A densidade técnica é dada pelo grau de artificialização do meio, cujas situações extremas corresponderiam, de um lado, ao meio natural e, de outro, ao meio construído com base em tecnologias indissociáveis da ciência e da informação. A densidade informacional, relativa à densidade técnica, corresponde àquela informação que se perfaz como ação por meio dos objetos. Ela informa o grau de exterioridade dos lugares, sua propensão a entrar em relação com outros lugares, que varia segundo setores e atores. Finalmente, a densidade comunicacional é o resultado da convivência cotidiana em copresença, marcada por relações de proximidade no espaço banal, criador de interdependências que se tornam obrigatórias pelo fato de ser geradas por situações nas quais os sujeitos compartilham o mesmo entorno. Trata-se de relações geradas no lugar, e apenas no lugar, a despeito de os objetos, os homens ou as ordens que os movem poderem ter origem distantes.

As multidões que têm ocupado tuas, espaços e prédios públicos em todo o mundo como estratégia de reivindicação parecem indicar ser impossível compreender a efetividade da ação fora dessa realidade inalienável que é o corpo e o lugar como condição dos acontecimentos. Para os estudantes secundaristas de São Paulo, não bastaram posts, trocas de informação e comunicação instantânea na rede. Foi preciso ocupar as escolas em 2015 e a Assembleia Legislativa do Estado de São Paulo em 2016 e colocar seus corpos em risco no campo de luta.

Inegavelmente, as redes permitem novas formas de organizar ações, de fazer circularem informações e de projetar os acontecimentos que são propagados mundo afora pela internet, em imagem e som. Mas são sempre sujeitos concretos, históricos, que alimentam as redes e sempre a partir de um lugar, como sede da decisão e meio da ação. As redes sociais online não anulam o espaço banal. Elas ampliam a multiplicidade de relações já postas pela pressão do fenômeno humano, sobretudo nas cidades. Ensejam ações articuladas, multilocalizadas e simultâneas pelos atuais movimentos sociais de diferentes agendas e matizes ideológicos, concorrendo para ampliar a densidade informacional e comunicacional dos lugares e dos eventos. Não desterritorializam a ação do protesto, cuja efetividade continua se dando com a multidão nas ruas. $\bigcirc$ que elas fazem é permitir que a ação, em tempo real, seja convergente em diferentes 
lugares, segundo novas estratégias, intensidades e percursos. Fato que faz com que essa mesma ação se desenrole segundo modos e razões híbridos, pois ao mesmo tempo estabelecidos nos lugares e em redes. Usadas por empresas, instituições, indivíduos e movimentos sociais, as redes informacionais concorrem para que o lugar, como extensão do acontecer solidário, se reafirme como funcionalização do mundo (Santos, 1996, p. 131), manifestação concreta que permite que se o perceba empiricamente.

\section{Referências}

AGAMBEN, G. O que é o contemporâneo e outros ensaios. Chapecó, SC: Argos, 2010.

BUSTAMANTE, J. Poder comunicativo, ecossistemas digitais e cidadania digital. In: SILVEIRA, S. A. (Org.). Cidadania e redes digitais. São Paulo: Comitê Gestor da Internet no Brasil/Maracá: Educação e Tecnologias, 2010. p. 12-35.

CASTELLS, M. Redes de indignação e esperança: movimentos sociais na era da internet. Rio de Janeiro: Zahar, 2013.

A galáxia da internet: reflexões sobre a internet, os negócios e a sociedade. Rio de Janeiro: Zahar, 2003.

CHARDIN, P.T. O fenômeno humano. São Paulo: Cultrix, 1995.

CRARY, J. 24/7: o capitalismo tardio e os fins do sono. São Paulo: Cosac Naify, 2014.

DI FELICE, M. O comum digital: as dimensões conectivas e o surgimento de um novo comunitarismo. Vida Pastoral, ano 56, n. 305, 2015. Edição Especial. Disponível em: http://www.vidapastoral.com.br/artigos/pastoral-e-comunicacao/o-comum-digital-as-dimensoes-conectivas-e-o-surgimento-de-um-novo-comunitarismo/. Acesso em: 1 jul. 2016.

Ser redes: formismo digital dos movimentos net-ativistas. MATRIZes, São Paulo, ano 7, n. 2, p. 49-71, jul./dez. 2013.

Netativismo: novos aspectos da opinião pública em contextos digitais. Artigo apresentado no International Association for Media and Communication Research, 2011. Disponível em: https://netativismo.files.wordpress.com/2011/10/artigo_massimodifelice.pdf. Acesso em: 30 jun. 2016.

FARIAS, P. S.; GOMES, M. M. T. Virtual e urbano: espaço e esfera pública em contexto digital. Z Cultural - Revista do Programa Avançado de Cultura Contemporânea, ano X, n. 1, 2015.

GOTTMANN, J. A evolução do conceito de território. Boletim Campineiro de Geografia, v. 2, n. 3, p. 523-545. 2012.

ISNARD, H. O espaço geográfico. Coimbra: Almedina, 1982. 
LATOUR, B. A esperança de Pandora. Bauru, SP: Edusc, 2001.

LEMOS, A. Espaço, mídia locativa e teoria ator-rede. Galáxia Online, São Paulo, n. 25, p. 52-65, jun. 2013.

LÉVY, P. Cibercultura. 3. ed. São Paulo: Editora 34, 2010.

A conexão planetária: o mercado, o ciberespaço, a consciência. São Paulo: Editora 34, 2001.

As tecnologias da inteligência: $\bigcirc$ futuro do pensamento na era da informática.

3. ed. São Paulo: Editora 34, 1993.

MARTINO, L. M. S. Teoria das médias digitais: linguagens, ambientes, redes. Petrópolis, RJ: Vozes, 2014.

MERLEAU-PONTY, M. Fenomenologia da percepção. 4. ed. São Paulo: WMF Martins Fontes, 2011.

OLIVEIRA, R. S. Ativismo digital e as novas mídias: desafios e oportunidades da cidadania em rede. Disponível em: https://nudiufsm.files.wordpress.com/2011/07/rafael-conpedi-mg. pdf. Acesso em: 26 jun. 2006.

ORTEGA, F. Corporeidade e biotecnologias: uma crítica fenomenológica da construção do corpo pelo construtivismo e pela tecnobiomedicina. Ciência $\mathcal{E}$ Saúde Coletiva, Rio de Janeiro, v. 12, n. 2, p. 381-382, 2007.

ORTEGA Y GASSET, J. A rebelião das massas. 3. ed. São Paulo: Martins Fontes, 2007.

O homem e a gente: intercomunicação humana. 2. ed. Rio de Janeiro: Livro lbero-Americano, 1973.

ROZA, E. A. Net-ativismo: comunicação e mobilização em contextos reticulares. Dissertação (Mestrado em Teoria e Pesquisa em Comunicação) - Escola de Comunicação de Artes, Universidade de São Paulo, São Paulo, 2012.

RÜDIGER, F. Breve história do pós-humanismo: elementos de genealogia e criticismo. Revista da Associação Nacional dos Programas de Pós-Graduação em Comunicação (e-compos), p. 1-17, 2007. Disponível em: http://www.compos.org.br/seer/ index.php/e-compos/article/viewFile/145/146. Acesso em: 2 jul. 2016.

SANTOS, M. Da totalidade ao Lugar. São Paulo: Edusp, 2005.

Por uma outra globalização. Rio de Janeiro/São Paulo: Record, 2000.

A natureza do espaço: espaço e técnica, razão e emoção. São Paulo: Hucitec, 1996.

Técnica, espaço, tempo: globalização e meio técnico-científico informacional. São Paulo: Hucitec, 1994.

SARTRE, J.-P. Crítica de la razón dialéctica. 4. ed. Buenos Aires: Losada, 1995.

SCHWARTZ, E. NetActivism: How Citizens Use the Internet. Newton, MA: O'Reilly, 1996. 
SENNET, R. Carne e pedra: o corpo e a cidade na civilização ocidental. Rio de Janeiro: BestBolso, 2014.

SILVEIRA, S. A. Ciberativismo, cultura hacker e o individualismo colaborativo. Revista USP, São Paulo, n. 86, p. 28-39, jun./ago. 2010.

. Novas dimensões da política: protocolos e códigos na esfera pública interconectada. Revista de Sociologia e Política, Curitiba, v. 17, n. 34, p. 103-113, out. 2009.

SORJ, B. Brasil@povo.com: a luta contra a desigualdade na Sociedade da Informação. Rio de Janeiro: Jorge Zahar/Brasilia, DF: Unesco, 2003. 